www.jmscr.igmpublication.org

Index Copernicus Value: 79.54

ISSN (e)-2347-176x ISSN (p) 2455-0450

crossrefDOI: https://dx.doi.org/10.18535/jmscr/v7i1.154

\title{
A 21 Year Old Female with Papillary Thyroid Carcinoma Arising from Thyroglossal Duct Cyst- A Rare Case Report
}

\author{
Authors \\ Dr Sai Sindhu Kotla ${ }^{1}$, Dr Sri Vidya.M ${ }^{2}$, Dr Milapshah ${ }^{3}$, Dr Sai Raj $^{4}$, Dr CN Srikanth \\ ${ }^{1}$ Dept of Pathology, Consultant, ${ }^{2}$ Dept of Pathology, Resident \\ ${ }^{3}$ Dept of Pathology, Consultant, ${ }^{4}$ Dept of Otorhinolaryngology, Consultant \\ ${ }^{5}$ Dept of Surgical Oncology, Consultant
}

\begin{abstract}
Thyroglossal duct cyst is the most common congenital cyst in anterior midline of neck at or immediately below hyoid bone. Mostly seen in children, young adults but may present at any age. Papillary carcinoma rising in thyroglossal cyst is a rare condition [<1\%]. Here we will describe a case of papillary carcinoma in thyroglossal cyst in a 21 year old female.
\end{abstract}

\section{Introduction}

The thyroid gland develops from endodermal cells of floor of pharynx in midline during third and fourth week of embryonic devlopment. These endodermal cells invaginate and descend from a blind hole in the base of the tongue [foramen caecum] through a diverticula across the midline in front of hyoid bone. The epithelial tract gets obliterated at eighth and tenth week and failure of this process leads to persistence of thyroglossal duct eventually developing into thyroglossal cyst. The incidence of thyroglossal duct cyst is estimated to be $7 \% .^{[2]}$

First case was described by Ucherman in 1911 followed by Brantano in 1915.Most common in children and young adults but can occur at any age. Malignancy arising in it is very rare constituting $1 \%$ of cases $^{[2]}$. Till now approximately 275 cases have been reported.

Among malignancy papillary thyroid carcinoma is most common variant accounting for $85 \%$ of cases in the $4^{\text {th }}$ and $5^{\text {th }}$ decade, another variant is squamous cell carcinoma which is more aggressive in nature compared to the former.

The thyroglossal duct cyst wall shows thyroid follicles and lined by columnar or squamous epithelium. ${ }^{(2)}$

\section{Case Report}

A 26 year old female patient was presented at outpatient department with swelling in front of neck. The swelling was measuring $2 * 2 \mathrm{~cm}$, it was painless nodular and cystic. The mass was mobile on deglutition and protrusion of tongue. Thyroid gland was normal on palpation. Physical examination revealed no associated cervical lymphadenopathy. Laboratory examination confirmed a euthyroid metabolic state without thyroid-specific medication. Thyroglobulin level was $8.2 \mu \mathrm{g} / \mathrm{L}$.

CT scan done revealed possibility of unusual location of thyroglossal duct cyst is likely with 
eccentric enhancing nodular soft tissue with calcified focus suggestive of neoplastic.

Then ultra sound guided fine needle aspiration was performed revealed features suspicious of papillary carcinoma.

The patient was treated surgically by routine sistrunk procedure; the cyst along with middle portion of hyoid bone was resected.

On Gross examination a cyst along with hyoid bone was recieved, cyst measuring $3 * 3 * 2 \mathrm{~cm}$.Cut section revealed a cyst filled with mucoid material and the cyst wall showing a focus of papillary excrescences measuring $1^{*} \quad 0.3^{*} 0.2 \mathrm{~cm}$.

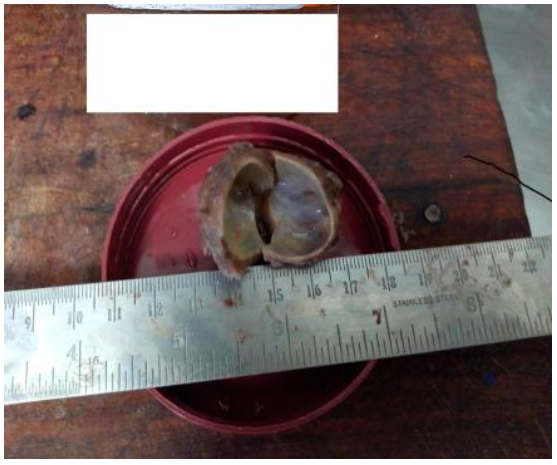

Figure 1: Gross picture showing cut opened cyst with papillary excrescences and mucoid material.

Microscopic examination revealed a cyst wall lined focally by cuboidal to squamous epithelium and shows papillary thyroid carcinoma infiltrating the wall, however soft tissue and hyoid bone were free of tumor. Also secondary degenerative changes such as calcification, squamous metaplasia, cholesterol clefts and hemorrhage were seen.

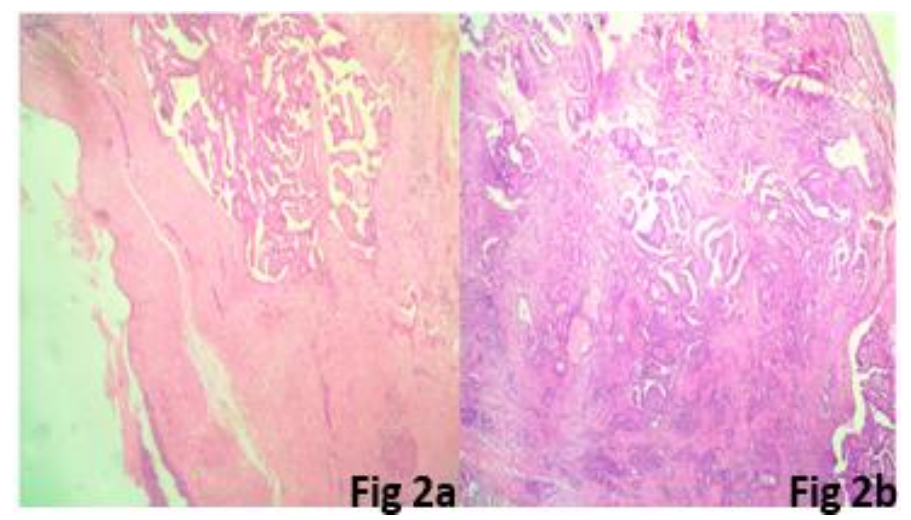

Fig 2a:Thyroglossal cyst with remnant squamous lining along with papillary thyroidcarcinoma (4x,H\&E) Fig 2b: (10x,H\&E)

\section{Discussion}

Thyroglossal duct cysts are the most common congenital anomalies of thyroid in the neck, estimated to occur in $7 \%$ of the adult population ${ }^{[2]}$. They are usually located in the anterior midline. Other infrequent locations include intralingual, suprahyoid [submental], and suprasternal areas Incidence of TGD carcinoma is a rare condition, of which papillary variant comprises of $94 \%$ and squamous variant comprises of $5 \%$. Theiretiology is unknown, hence preoperative diagnosis is difficult. The incidence of papillary carcinoma arising in the thyroglossal duct cyst is $<1 \%$. The diagnosis is often made postoperatively on histological examination of the resected specimen. The age of presentation ranges from 6 to 81 years with an average age of 39 years. Clinical presentation is similar to that of benign cysts. Women are affected more commonly than men. Primary carcinoma arising from the epithelium lining the cyst has been described in a few cases ${ }^{[3]}$. Metastases were mentioned in only $7.7 \%$ of cases. Metastasis can occur to ovary, breast, gastrointestinal tract and thyroid. ${ }^{(4)}$

To our knowledge, distant metastases from papillary thyroid carcinoma in a TGDC at the stage of diagnosis have never been reported so far. However, cervical lymph node metastases are prevalent in $7.7 \%$ to $15 \%$ of the cases ${ }^{(1)}$

The surgical procedure performed commonly for a thyroglossal duct cyst is Sistrunk's procedure. This procedure consists of removal of the thyroglossal duct cyst along with middle portion of the hyoid bone and a core of tissue surrounding the duct to open into the oral cavity at the foramen cecum. Although some surgeons consider the Sistrunk's procedure to be adequate if histological examination do not show any extracystic extension. Some literatures suggest more aggressive surgical approaches based on the finding that papillary thyroid carcinoma may spread through the thyroglossal duct remnant even with no lesion detected clinically in the gland itself. Those literatures suggest that patients be treated with Sistrunk procedure, total 
thyroidectomy, postoperative radioactive iodine therapy, and thyroid hormone replacement ${ }^{[3]}$.

The concurrent appearance of papillary carcinoma thyroid was reported in about $20 \%$ cases of TGDC carcinoma, thus it is important to differentiate primary papillary carcinoma arising in a TGDC from those of metastatic papillary carcinoma thyroid. The following three criteria are essential for the diagnosis of primary carcinoma arising in a TGDC. (1) Presence of carcinomatous component in the wall of TGDC, (2) presence of normal thyroid tissue adjacent to the tumor, (3) presence of clinically normal thyroid gland without evidence of any primary thyroid carcinoma. Our case fulfils all these three criteria. Sistrunk operation is the procedure of choice for this condition, however, some authors recommended further total thyroidectomy, if the carcinomatous component in TGDC is more than $1 \mathrm{~cm}$ in size and even if the tumor is $<1 \mathrm{~cm}$ but show enlarged cervical lymph node, tumor invasion of the cyst wall or abnormal thyroid gland. Although prognosis of papillary carcinoma arising in a TGDC is excellent with reported occurrence of metastatic lesion in $<2 \%$ of cases, however, considering the multifocal nature of papillary carcinoma, a careful long-term follow-up is recommended ${ }^{[5]}$.

\section{Conclusion}

Because TGDC carcinoma is very rare, diagnosis may be missed, thus affecting the accuracy of the treatment provided. Surgeons should be aware of extended surgery including total thyroidectomy and/or neck node dissection TGDCa in surgical planning and postoperative treatment. Regular follow-up to detect any recurrence in the thyroid gland is essential, particularly in cases where the thyroid gland is not resected.

\section{References}

1. Ectopic papillary thyroid carcinoma within a thyroglossal duct cyst: A case report Natasha Roehlen, MD, Szilvia Takacs, MD and Katharina laubner,MD; 2017

2. Incidental papillary thyroid carcinoma in thyroglossal duct cyst case report Ana Karen Lira Medina,a Eliseo Fernandez Berdeal,b Ernesto Bernal Cisneros,c Rebeca Betancourt Galindo,d and Pamela Frigerioe, $\star$ Int J Surg Case Rep. 2016; 29: 4-7.

3. Papillary Carcinoma Occurrence in a Thyroglossal Duct Cyst with Synchronous Papillary Thyroid Carcinoma without Cervical Lymph Node Metastasis: TwoCases Report F. B. Sobri, * M. Ramli, U. N. Sari, M. Umar, and D. K. Mudrick

4. Papillary carcinoma arising in a thyroglossal duct remnant Kamal Kant, Girish Rajpal.Indian Journal of Surgery, Vol. 65, No. 3, May-June, 2003, pp. 282284

5. An incidental primary papillary carcinoma arising in a thyroglossal duct cyst: Report of a rare finding Mohammad Jaseem Hassan, Safia Rana, Sabina Khan, Zeeba Shamim Jairajpuri, Seema Monga , Abhinav Jain , Sujata Jetley Volume : 8 | Issue : 1 | Page : 62-64. 